Olena Polovynko - PhD, Associate Professor, Research and Teaching Associate at the University of Strasbourg, France e-mail: polovynko@unistra.fr

Сведения об авторах: Светлана Витальевна Короткова - кандидат филологических наук, доцент, Национальный ТУ «Днепровская политехника», Днепр Украина

e-mail: sveta korotkova@i.ua

Елена Алексеевна Половинко - кандидат филологических наук, ассоциированный профессор, Страсбургский университет, Страсбург Франция

e-mail: polovynko@,unistra.fr

Manuscript received: 05/02/2019 Accepted for publication: 09/20/2019

DOI:

\title{
REGULARITY OF NATIVIZATION OF EXOTICISMS: LOANWORDS FROM THE SOUTH-ASIAN LANGUAGES IN THE CURRENT ENGLISH PRESS
}

\author{
Marina Kuzina \\ Candidate of Philology, Associate Professor \\ Moscow Pedagogical State University \\ (Moscow, Russian Federation) \\ e-mail: kouzina-marina@yandex.ru
}

\begin{abstract}
Conveying the foreign, alien background in poetry, plays, short stories and novels has traditionally been regarded as the major aim of resorting to exotic vocabulary in belles-lettres. In the present article the statistics are presented to highlight the regular usage of South Asian exoticisms in a wider range of the English functional styles. The functional assimilation of the analyzed lexical loanwords is revealed through comparing dictionary entries (to denote the retaining or loss of the culturally loaded component of the meaning) and their actual usage in the British and American newspapers ("The Guardian", "The Independent", "USA Today", "Washington Post"). The analysis of the current usage of exotic loanwords of South Asian origin contributes to the understanding of the conditions for the de-exoticization, i.e. nativization of exotic vocabulary. Among these the following features can be named: belonging to the groups of adjectives or verbs; relatively high level of the abstract meanings of the exotic nouns; the frequent occurrence in contemporary written journalese style; the topical socio-cultural context of its usage.
\end{abstract}

Keywords: South Asian loanwords; exotic word/exoticism; de-exotization; culture-loaded meaning

\section{ЗАКОНОМЕРНОСТИ ПРОЦЕССА ДЕЭКЗОТИЗАЦИИ (НА ПРИМЕРЕ ФУНКЦИОНИРОВАНИЯ ЗАИМСТВОВАНИЙ ИЗ ЯЗЫКОВ ЮЖНОЙ АЗИИ В СОВРЕМЕННОЙ АНГЛОЯЗЫЧНОЙ ПРЕССЕ)}

\author{
Марина Кузина \\ Кандидат филологических наук, доцент \\ Московский педагогический государственный университет \\ (Москва, Российская Федерация) \\ e-mail: kouzina-marina@yandex.ru
}

\begin{abstract}
Аннотация. Создание образа инонациональной речевой среды в художественной литературе традиционно рассматривается как основная цель употребления экзотической лексики в данном функциональном стиле. В данной статье приводятся статистические данные, свидетельствующие об активном употреблении ряда заимствований из языков Южной Азии в более широком диапазоне функциональных стилей современного английского языка. Особенности протекания процесса деэкзотизации устанавливаются путём анализа этимолого-культурологических помет в вокабулах с экзотизмом в качестве заголовочного слова, а также посредством привлечения контекстов их фактического употребления на страницах британских и американских периодических изданий («The Guardian», «The Independent», «USA Today», «Washington Post»). Изучение употребления южно-азиатских экзотизмов в современных англоязычных периодических изданиях позволяет сделать выводы об условиях утраты ими национально-культурной составляющей семантики: отнесение к классам имен прилагательных или глаголов, достаточно высокий уровень абстрактности у имён существительных, актуальный социокультурный контекст употребления и высокая частотность употребления.
\end{abstract}

Ключевые слова: заимствования из языков Южной Азии; экзотизм; деэкзотизация; национально-культурный компонент значения 
ВВЕДЕНИЕ. В настоящее время ряд экстралингвистических факторов: рост численности южноазиатской диаспоры в Великобритании, США и Канаде; увеличение числа англоязычных и двуязычных печатных изданий и электронных СМИ для азиатских диаспор в метрополиях; растущая популярность мультикультурных художественных произведений (и их экранизаций) - способствует проникновению слов из языков Южной Азии в современный английский язык. Ряд лингвистов и журналистов настаивают на более активном использовании лексики, заимствованной из языков полуострова Индостан, ввиду их лаконичности, метафоричности и наличия в современном английском языке определённых лексических лакун: «Indianisms are a perfectly valid form of English - as are Americanisms - excluded only by rank snobbery. They should form part of our language's global vocabulary» (The Guardian, 4/01/2016).

Большую часть лексических единиц индийского происхождения принято относить к экзотической лексике, то есть к словам иноязычного происхождения, обозначающим реалии чужой культуры - реалии, которые отсутствуют (или отсутствовали) в культуре языка-реципиента (Marinova, 2008). Акцентирование такой функции экзотизмов, как создание образа инонациональной речевой среды именно в художественной литературе, закрепилось в отечественном языкознании (Bulakhovskiy, Inyutina, Krysin, Mikhailovskaya, Samotik, Filin, Shmelyov atc..).

Для многих лексем, возводимых к тому или иному этимону в группе южноазиатских языков, характерна высокая частотность употребления (десятки тысяч случаев употребления на одно периодическое издание) в целом спектре разнообразных контекстов в современных средствах массовой информации на английском языке, что позволяет отметить предпосылки к деэкзотизации одного или ряда их значений.

ОБЗОР ЛИТЕРАТУРЫ. Незначительное число исследователей английского языка приводит списки заимствований, возводимых к этимонам в санскрите, хинди, урду и других языках Южной Азии. В.В. Скит (1911) в кратком словаре английского языка размещает словник из 71 лексемы интересующего нас происхождения, Н.Н. Амосова (1956) приводит 21 слово данного происхождения, В.П. Секирин (1964) - 38 лексем, в монографии Ф. Дуркина (2014) находим 53 лексические единицы.

Особый интерес представляет словарь «A Glossary of Colloquial Anglo-Indian Words and Phrases, and of Kindred Terms, Etymological, Historical, Geographical and Discursive», или «Hobson-Jobson», изданный в 1886 году Г. Юлом и А. Бернеллом: первый словарь англо-индийского языка, постраенный на исторических принципах. Этому первому опыту регистрации лексики южно-восточного происхождения в английском языке следовали многие другие исследователи экзотической лексики в словарном составе английского языка, в частности: Дж. Витворт «Anglo-Indian Dictionary» (1885), Г. Вильсон «Glossary» (1885), Дж. Субба Paо «Indian Words in English» (1945), Р.Е. Хокинс «Common Indian Words in English» (1984), И. Льюис «Sahibs, Nabobs and Boxwallahs. A Dictionary of the Words of Anglo-India» (1991) (Bitko, 2013).

В современных электронных словарях издательств Оксфордского университета и Мэриам-Вебстер представляется невозможным точно определить число учтённых заимствований южноазиатского происхождения (не менее 500 слов), а учебные словари обычно включают около сотни заимствований_данного происхождения: учебные словари издательства Пирсон-Лонгман в 1995 году регистрировали 126 единиц 1995 году и 132 единицы в издании 2015 года.

Следует отметить значительное преобладание количества работ по проблемам деэкзотизации лексики, заимствованной в русский язык, над работами по утрате национально-культурного компонента у заимствований в английском языке К числе первых отнесём диссертационные исследования В.М. Феоклистовой (1999), И.В. Федосеевой (2003), Н.В. Вагановой (2005), Э.А. Китаниной (2005), Е.В. Мариновой (2008), М.Б. Геращенко, О.И. Александровой (2010), Е.Е. Козловой (2012). Общетеоретические проблемы влияния языков Южной Азии на современный английский язык становятся предметом изучения ряда отечественных и зарубежных учёных, в частности Н.С. Битко, М.А, Блинов, Н.А. Вишневская, Е.П. Зыкова, Н.А. Милютина, Н.В. Тененёва, А.Н. Попова, А. R. Wadia, Sh. Bhatia, K. Teltscher.

МЕТОДЫ ИССЛЕДОВАНИЯ. Цель настоящей публикации = выявить закономерности деэкзотизации заимствований из индийской группы индоевропейской семьи. На примере употребления узуальных экзотизмов guru, juggernaut, karma, mantra, nirvana, относящихся к тематической группе «религиозные понятия буддизма и индуизма», в ведущих британских и американских изданиях анализируются условия приобретения заимствованием способности обозначать реалию языка-реципиента и, как следствие, переходить из языковой периферии в ядро принимающего языка. Общее число выявленных примеров употреблений вышеприведённых слов составило более 140.000. Выводы о протекании процесса деэкзотизации сделаны как на основании этимолого-культурологических помет в вокабулах с экзотизмами в качестве заголовочных слов («The Oxford English Dictionary», «The Merriam-Webster Dictionary»), так и путём анализа контекстов их фактического употребления на страницах британских и американских периодических изданий («The Guardian», «The Independent», «USA Today», «Washington Post»).

РЕЗУЛЬТАТЫ И ДИСКУССИЯ. Первым этапом систематизации условий функциональной ассимиляции индийских реалий, при которых они переходят из разряда «чужого» (экзотизмов, денотативное значение которых не способно обозначать денотат языка-реципиента) в «своё» (частично или полностью ассимилировавшиеся заимствования, обозначающие в том числе и денотаты языка-реципиента) является распределение экзотизмов на группы на основании трёх критериев: количества семем, сохранения ими национально-культурного компонента, характера этимолого-культурологических помет в вокабуле.

Весь корпус заимствований из языков Южной Азии, зарегистрированных в том или ином моноязычном или переводном словаре английского языка, можно условно разделить на три группы. К первой группе отнесём 
слова с одним деэкзотизированными значением, например: «bandanna/bandana, bangle, bungalow, calico, cashmere, catamaran, cheetah, cheroot, chintz, chutney, coir, cot, cummerbund, cushy» (The Merriam-Webster; the Oxford English Dictionary). Эти лексические единицы не сопровождаются самостоятельной и(ли) интегрированной культурно-этимологической пометой, а их вокабула может содержать несколько контекстов типичного употребления. В процентном отношении данные слова составляют почти половину от всех регистрируемых лексикографическим изданием южноазиатских заимствований.

Вторая группа представлена многозначными заимствованиями, некоторые значения которых регистрируются словарями как культурно немаркированные, а другие - как обозначающие именно денотат языка-донора, а не языка-реципиента: avatar, guru, karma, mandarin, mantra, nirvana, pariah, pajamas/pyjamas, purdah, teak, yoga, что предполагает размещение культурно-этимологического комментария у каждой семемы в вокабуле (The Merriam-Webster; the Oxford English Dictionary). Несмотря на то что в процентном отношении это самый незначительный пласт лексем южноазиатского происхождения, они характеризуются наиболее высокой частотностью употребления, самой развитой сочетаемостью и могут не восприниматься носителями английского языка как «чужие» слова.

В третью группу вошли заимствования, единственное значение которых способно указывать только на денотат языка-донора, что обязывает лексикографов снабжать их вокабулы самостоятельной и / или интегрированной культурно-этимологической пометой. Чуть более половины зарегистрированных в лексикографических источниках слов индийского происхождения относится именно к этой группе, например: ashram, ayah, baboo/babu, banyan, begum, Bengali, betel, bhaji/bhajee, biriani/byriani, Blighty, Brahman/Brahmin, Buddhism, Buddhist, chador, chai, chakra, coolie, cowrie, curry (The Merriam-Webster; the Oxford English Dictionary). Собственно экзотическая лексика употребляются на страницах современных британских и американских СМИ исключительно редко (не более сотни употреблений для отдельно взятой лексемы): журналисты к ней обращаются при необходимости назвать и описать южноазиатские эндемики, продукты и блюда, предметы одежды, виды транспорта, жилища, бытовые приборы, сырьё, профессии, вероисповедание, исторические и современные обычаи и традиции.

Второй этап описания закономерностей процесса деэкзотизации значений включает в себя анализ контекстов употребления наиболее частотных заимствований (guru, juggernaut, karma, mantra, nirvana) - с одним или несколькими деэкзотизированными значениями. Данные лексемы обозначают базовые понятия буддизма и индуизма, зародившихся на полуострове Индостан, и могут быть возведены к соответствующему слову-прототипу в санскрите. Современные лексикографические источники непоследовательны в регистрации культурно маркированных и деэкзотизированных семем в рамках одной словарной статьи. Так, у заимствования mantra культурно-маркированное значение фиксируется первым («(originally in Hinduism and Buddhism) a word or sound repeated to aid concentration in meditation; a Vedic hymn»), а деэкзотизированное значение - вторым («а statement or slogan repeated frequently»). Однако для лексемы juggernaut вокабула строится по принципу «от производных (деэкзотизированных) значений к изначальным (экзотическим) значениям»: 1. a huge, powerful, and overwhelming force; 2. (British) a large, heavy vehicle, especially an articulated lorry; 3. (old-fashioned name for Jagannatha) the form of Krishna worshipped in Puri, Orissa, where in the annual festival his image is dragged through the streets on a heavy chariot; devotees are said formerly to have thrown themselves under its wheels (The Oxford English Dictionary).

Для анализируемых заимствованных единиц характерно исключительно активное употребление на страницах современной англоязычной прессы. Изучение архива онлайн-версии британских газет «Тhе Guardian» и «The Independent», показывает, что guru употребляется соответственно более 35.500 раз и 20.500 раз, mantra - более 20.400 раз и 7.200 раз, karma - более 16.820 раз и 1.710 раз, nirvana - более 7.200 раз и 3.680 pa3, juggernaut - более 5.280 раз и 1.960 раз. <..> Иные тенденции употребляемости демонстрируют изучаемые заимствования в американских периодических изданиях «USA Today» и «Washington Post»: mantra употребляется соответственно 2.088 раз и 4.374 раз, guru - 2.073 раз и 3.978 раз, juggernaut - 1.368 раз и 2.218 раз, karma - 882 раз и 1.502 раз, nirvana - 557 раз и 974 раз (The Guardian; the Independent; the Washington Post; USA Today).

При этом в большинстве случаев данные заимствования употребляются в культурно немаркированных значениях. Так, в статьях по проблемам выхода Великобритании из Европейского союза заимствование mantra употребляется в широком значении «мысль, которая постоянно повторяется и должна быть воспринята без обдумывания», а не в узкоспециальном значении «священный гимн в индуизме и буддизме, требующий точного воспроизведения звуков, его составляющих»: Together with three other MPs, Creagh has written a thundering article in the Northern Echo and the Yorkshire Post denouncing this patronising nonsense, denying the southern caricature that "we northern Labour MPs live in constant fear of losing our seats" and "unless we repeat that mantra that leave means leave ... we are all heading for the political scrapyard" (The Guardian 30/04/2019).

Анализируемые заимствования также часто выносятся журналистами в газетные заголовки, что скорее объясняется частым использованием данных слов общественными деятелями, чем их едва ощутимым экзотическим характером. Следующие заголовки статей на политические, экономические, экологические и прочие актуальные темы можно рассматривать как типичные для современной англоязычной прессы: David Cameron accused of idiocy over austerity mantra; Theresa May's new year mantra: Brexit means compromise; 'Pics or it didn't happen' - the mantra of the Instagram era (The Guardian).

Кроме того, изучаемые заимствования демонстрируют тенденцию к расширению значения (или к образованию новых семем). Так, juggernaut в значении «слепая непреклонная сила» может относиться к лицу 
(или группе лиц), к продукту человеческой деятельности, к абстрактному понятию и т. д. Многочисленны примеры контекстов, в которых масштабный ТВ проект, сериал или фильм бьёт рекорды просмотров, что позволяет сравнить его с колесницей бога Джаганнатхи (Кришны), которая идёт напролом, не взирая на любые препятствия: As Nielsen begins tracking viewership, HBO's departing fantasy hit "Game of Thrones" continues to show muscle as a ratings juggernaut (USA Today).

Также справедливо отметить, что деэкзотизированные заимствования часто удовлетворяют потребность в лаконичной и точной номинации. Например, при описании перехода от пятидневной к четырёхдневной рабочей недели в одном из американских офисов отмечается, что подобную смену рабочего графика нельзя охарактеризовать как «нирвану, свободную от проблем, недовольств, желаний что-то улучшить»: He decided to try a four-day workweek instead. A year later, Andersen said it's working well, but "it isn't nirvana”. With the exception of a receptionist, all his employers get Friday off and work slightly longer days Monday through Thursday. On those days, he's learned to schedule in blocks of break time to keep people productive, cater lunch and not schedule meetings on Thursdays, when everyone is focused on getting out the door (The Washington Post).

ЗАКЛЮЧЕНИЕ.Результаты проведённого эксперимента позволяют утверждать, что на процесс деэкзотизации у заимствований из языков Южной Азии напрямую не влияют следующие факторы: хронологическая характеристика, тематическая принадлежность, степень формальной ассимиляции, слово-прототип для каждой конкретной лексемы.

К условиям утраты экзотизмами национально-культурной составляющей семантики справедливо отнести следующее: особая частеречная принадлежность (отнесение к классам имен прилагательных или глаголов), достаточно высокий уровень абстрактности у имён существительных (наличие хотя бы одного абстрактного значения у двузначного экзотизма облегчает его соотнесение с более широким спектром денотатов), высокая частотность употребления, причём в общественно значимых контекстах.

\section{LIST OF REFERENCES}

Bitko N.S. Yazykovye kontakty kak faktor formirovaniya leksikona indijskogo varianta anglijskogo yazyka // Zapiski z romanogermanskoj filologii. 2013. № 1 (30). =-Str. 17-24.

Marinova E.V., Teorija zaimstvovanija v osnovnyh ponjatijah i terminah: slovar'-spravochnik, Moscow, FLINTA Nauka, 2013. (in Russian)

The Guardian // https://www.theguardian.com [30.04.2019].

The Independent // https://www.independent.co.uk [30.04.2019].

The Merriam-Webster Dictionary // https://www.merriam-webster.com [30.04.2019]

The Oxford English Dictionary // https://en.oxforddictionaries.com [30.04.2019].

The Washington Post // https://www.washington post.com [30.04.2019].

USA Today // https://www.usatoday.com [30.04.2019].

\section{For citation:}

Kuzina Marina (2019) REGULARITY OF NATIVIZATION OF EXOTICISMS: LOANWORDS FROM THE SOUTH-ASIAN LANGUAGES IN THE CURRENT ENGLISH PRESS // International Scientific-Pedagogical Organization of Philologists “ WESTEAST ” (ISPOP). Scientific Journal WEST-EAST. Vol 2/1 N1 (October, 2019). pp. 85-88. doi:

\section{Для цитирования:}

Кузина Марина (2019) ЗАКОНОМЕРНОСТИ ПРОЦЕССА ДЕЭКЗОТИЗАЦИИ (НА ПРИМЕРЕ ФУНКЦИОНИРОВАНИЯ ЗАИМСТВОВАНИЙ ИЗ ЯЗЫКОВ ЮЖНОЙ АЗИИ В СОВРЕМЕННОЙ АНГЛОЯЗЫЧНОЙ ПРЕССЕ) // Internationa 1Scientific-Pedagogical Organization of Philologists “WEST-EAST ” (ISPOP). Scientific Journal WEST-EAST. Vol 1/1 N1 (October, 2019). C. 85-88. doi:

Information about the author: Kuzina M.A. - PhD in Philology, Associate Professor, Department of Phonetics and Lexicology of English Language, Faculty of Foreign Languages, Moscow State University of Education

e-mail: kouzina-marina@yandex.ru

Сведения об авторе: Кузина Марина Анатольевна - кандидат филологических наук, доцент кафедры фонетики и лексики английского языка, Институт иностранных языков, Московский педагогический государственный университет e-mail: kouzina-marina@yandex.ru 